\title{
RELASI ANTARA MATA PELAJARAN AKIDAH-AKHLAK PADA TRADISI BERANDEP
}

\author{
Dewi Nurhayati 1 ) \\ Wahab ${ }^{2)}$ * \\ ${ }^{1}$ Institut Agama Islam Negeri Pontianak \\ ${ }^{2}$ Institut Agama Islam Negeri Pontianak \\ *E-mail: abdulwahabassambasi@gmail.com
}

\begin{abstract}
The culture of the Malay people of Sungai Jambu has local wisdom that is in the tradition of being deported in fields that are held once a year. Berandep in the fields is the activity of the Malay community in Sungai Jambu which is carried out in mutual cooperation at the time of planting (planting rice) and harvesting rice (tapping rice) with the aim of making the work is easier to finish. In the implementation of berandep formed 4-6 people and carried out in turns. In this study, researchers used a qualitative approach with ethnographic methods. Based on the tradition of research based on the above, that from the implementation of the tradition there are behaviors that lead to cooperation and helping one another, in the sense that the subject of continuous akidah-akhlak is based on tradition. The implementation of the backward tradition has a relation to the subjects of Akidah-Akhlak which are outlined in the material of cooperation, good help, and morals in neighboring and community life.
\end{abstract}

Keywords: Local Wisdom, Akidah-Akhlak lessons, Berandep

\begin{abstract}
Abstrak
Kebudayaan masyarakat Melayu Dusun Sungai Jambu memiliki kearifan lokal yang ada pada tradisi berandep di ladang yang dilaksanakan satu tahun sekali. Berandep di ladang adalah aktivitas masyarakat Melayu Dusun Sungai Jambu yang dilaksanakan secara gotong royong pada saat menanam (nandor padi) dan memanen padi (mengetam padi) dengan tujuan agar mempermudahkan pekerjaan cepat selesai. Dalam pelaksanaan berandep terbentuk sebanyak 4-6 orang dan dilaksanakan secara bergiliran. Dalam penelitian ini, peneliti menggunakan pendekatan kualitatif dengan metode etnografi. Berdasarkan penelitian tradisi berandep di atas, bahwa dari pelaksanaan tradisi tersebut terdapat perilaku yang mengarahkan pada kerja sama dan tolong-menolong terhadap sesama, dalam arti mata pelajaran Akidah-Akhlak berkesinambungan terhadap tradisi berandep. Pelaksanaan tradisi berandep terdapat relasi pada mata pelajaran Akidah-Akhlak yang dituangkan dalam materi kerja sama, tolongmenolong dan akhlak yang baik dalam hidup bertetangga dan bermasyarakat.
\end{abstract}

Kata Kunci: Kearifan Lokal, Pelajaran Akidah-Akhlak, Berandep

\section{PENDAHULUAN}

Berkaitan dengan akhlak mulia, tentu saja ada hubungannya dengan kerja sama dan tolong-menolong. Menurut Abdulsyani (1994:156), kerja sama adalah suatu bentuk proses sosial, dimana didalamnya terdapat aktivitas tertentu yang ditunjukkan untuk mencapai tujuan bersama dengan saling membantu dan saling memahami aktivitas masing-masing. Selain itu, pengertian tolong-menolong akan dipaparkan oleh para ahli di bawah ini. 
Winardi (2009:91) menyatakan tolong menolong termasuk akhlak terpuji. Kita tidak dapat hidup sendiri tanpa bantuan atau pertolongan orang lain. Perilaku tolong menolong dapat mendatangkan banyak manfaat yaitu antara lain sebagai berikut: Pekerjaan yang berat akan menjadi ringan, masalah yang sulit menjadi mudah, dapat terjalin kerukunan antar dengan orang lain, orang lain akan merasa senang menolong kita dan mempunyai banyak teman.

Barmawie Umarie (1995:53) Tolong menolong adalah ciri kehalusan budi, kesucian jiwa, ketinggian akhlak dan membuahkan cinta antar teman, solidaritas dan penguat persahabatan dan persaudaraan. Abduh Gholib Ahmad Isa (2010:38) Islam menganjurkan setiap orang Islam agar menjadikan tolong-menolong sebagai ciri dan sifat dalam mu"amalah sesama mereka.

Pendapat yang demikian juga dikemukakan Mohammad Daud Ali (2004: 356359) bahwa "ruang lingkup akhlak salah satunya adalah akhlak terhadap tetangga antara lain saling mengunjungi, saling memberi, dan saling menghormati. Lebih lanjut Hasan (dalam Rosihon Anwar, 2008: 243) menyatakan orang mukmin akan tergerak hatinya apabila melihat orang lain tertimpa kerusakan untuk menolong mereka sesuai dengan kemampuannya. Apabila tidak ada bantuan berupa benda, kita dapat membantu orang tersebut dengan nasihat atau kata-kata yang dapat menghibur hatinya. Bahkan, sewaktu-waktu bantuan jasa pun lebih diharapkan daripada bantuanbantuan lainnya.

Kementerian Agama RI (2011:349) Tolong menolong didalam Islam disebut dengan ta"awun. Di dalam Islam ta"awun tidak dapat direalisasikan dalam setiap kehidupan manusia, karena bagi setiap muslimin tolong menolong harus dengan cara yang sesuai dengan keadaan objek orang yang bersangkutan. Islam mengajarkan kepada umatnya agar mau bekerja sama, tolong-menolong dengan sesamanya atas dasar kekeluargaan. Allah SWT, berfirman dalam surat al-Maidah ayat 2,

Dan tolong-menolonglah kamu dalam (mengerjakan) kebajikan dan takwa, dan jangan tolong-menolong dalam berbuat dosa dan permusuhan. Bertakwalah kepada Allah, sungguh, Allah amat besar siksa-Nya.

M. Quraish Shihab (2014:14) dari ayat di atas dapat dilihat bahwa tolong menolong yang diperintahkan oleh Allah SWT adalah tolong menolong untuk kebaikan dan takwa kepada Allah. Allah mengajarkan kaum muslimin untuk saling menolong diantara mereka dalam segala kondisi maupun keadaan, karena dalam perbuatan 
saling menolong tersebut merupakan prinsip dasar dalam menjalin kerja sama dengan siapapun.

Mengenai pengertian tolong-menolong di atas, terdapat pada mata pelajaran Akidah-Akhlak yang mana dikemukakan oleh Andi Prastowo (2015:161-162) menyatakan dengan berdasarkan pada Standar Kompetensi Lulusan, Standar Kompetensi dan Kompetensi Dasar, secara lebih spesifik, mata pelajaran AkidahAkhlak di Madrasah Ibtidaiyah salah satunya adalah aspek akhlak yang terdiri dari pembiasaan akhlakul karimah, yaitu: disiplin, hidup bersih, ramah, sopan-santun, syukur nikmat, hidup sederhana, rendah hati, jujur, rajin, percaya diri, kasih sayang, taat, rukun, tolong-menolong, hormat dan patuh, siddiq, amanah, tablig, fathonah, tanggung jawab, adil, bijaksana, teguh pendirian, dermawan, optimis, qona'ah, tawakkal, kesederhanaan, toleransi, dan cinta.

Jadi, peneliti menyimpulkan bahwa manfaat tolong-menolong pada mata pelajaran Akidah-Akhlak erat kaitannya dengan perilaku terpuji siswa-siswi. Perilaku yang baik atau terpuji akan menghasilkan atau membuahkan perilaku yang akan tertanam dalam pribadi anak. Maksudnya adalah pribadi anak yang terbiasa berbuat baik akan menjadi kebiasaan dalam lingkungan baik di rumah, di sekolah, maupun di masyarakat. Hal ini perlu ditekankan bahwa perilaku terpuji baik di rumah, sekolah maupun di masyarakat terus-menerus diterapkan baik kepada orang tua, guru, dan anak-anak.

Selain itu, perilaku terpuji pada mata pelajaran Akidah-Akhlak juga diterapkan di lingkungan masyarakat. Salah satunya pada masyarakat Melayu Dusun Sungai Jambu yang terus-menerus melaksanakan tradisi berandep di ladang yang dilakukan secara gotong-royong (kerja sama) di bidang pertanian. Tradisi ini dilakukan, karena masyarakat setempat merasa puas apabila dilakukan secara bersama-sama dan pekerjaan cepat selesai. Selain itu, keunikan tradisi berandep pada masyarakat Melayu Dusun Sungai Jambu adalah berbagi minuman dan makanan bagi perilaku berandep. Tidak hanya itu, walaupun perilaku berandep dalam keadaan sulit perekonomiannya senantiasa membawa minuman dan makanan apa adanya dan lebih-lebihnya lagi perilaku berandep menghargai pemberiaan sesama mereka.

Hal ini membuat peneliti menjadi tertarik meneliti tradisi berandep pada masyarakat Melayu Dusun Sungai Jambu. Karena tradisi tersebut ada relasi pada mata pelajaran Akidah-Akhlak. Oleh karena itu, tradisi berandep menawarkan perilaku 
terpuji di kalangan masyarakat Dusun Sungai Jambu. Hanya saja tradisi berandep terdiri 4-6 orang saja. Maka dari itu, peneliti akan menawarkan kepada masyarakat setempat bahwa tradisi berandep di ladang juga diajarkan kepada anak-anak atau melibatkan anak dalam proses pelaksanaan menanam maupun memanen padi.

\section{METODE}

Wahab (2015:254) Berdasarkan tujuan yang ingin dicapai penelitian ini menggunakan pendekatan kualitatif dengan metode etnografi. Etnografi melibatkan pengamatan yang luas terhadap kelompok. Para etnografer mempelajari makna dari perilaku, bahasa, dan interaksi di kalangan para anggota kelompok berkebudayaan sama tersebut.

Adapun kegunaan dari metode etnografi adalah untuk mencoba memahami makna perbuatan dan kejadian bagi orang yang bersangkutan menurut kebudayaan dan pandangan mereka sendiri. Dalam penelitian etnografi, peneliti lebih banyak bertindak sebagai orang yang belajar kepada pendukung kebudayaan, sehingga peneliti dapat memahami dan menganalisis budaya masyarakat. Dari pemahaman ini, maka setting penelitian ini adalah masyarakat Melayu Dusun Sungai Jambu Kabupaten Kayong Utara yang melaksanakan tradisi berandep di ladang. Subjek penelitian dalam penelitian ini adalah pelaku tradisi berandep di ladang. Adapun informan yang dimaksud adalah Ibu Juliana, Langna, Sahibah, Ayu, Biah dan Endang. Teknik yang digunakan untuk memperoleh informasi atau data adalah wawancara melalui via telepon pada pelaku tradisi berandep di ladang.

Jadi, peneliti menyimpulkan bahwa metode etnografi dari beberapa pendapat di atas, metode tersebut menafsirkan budaya ataupun kearifan lokal yang terdapat pada kebudayaan yang sama dalam kehidupan berkelompok. Maka dari itu, metode etnografi terdapat kaitannya dengan tradisi berandep yang mana proses pelaksanaannya dikerjakan secara bersama-sama atau berkelompok.

\section{KAJIAN TEORI}

Menurut Peraturan Menteri Agama Republik Indonesia Nomor 2 Tahun 2008 tentang Standar Kompetensi Lulusan dan Standar Isi Pendidikan Agama Islam dan Bahasa Arab di Madrasah Mata pelajaran Akidah-Akhlak di Madrasah Ibtidaiyah berisi pelajaran yang dapat mengarahkan kepada pencapaian kemampuan dasar peserta didik untuk dapat memahami rukun iman dengan sederhana serta pengamalan dan 
pembiasaan berakhlak Islami secara sederhana pula, untuk dapat dijadikan perilaku dalam kehidupan sehari-hari serta sebagai bekal untuk jenjang pendidikan berikutnya. Ruang lingkup mata pelajaran Akidah-Akhlak di Madrasah Ibtidaiyah salah satunya dengan pembiasaan akhlak karimah (mahmudah) yang disajikan pada tiap semester dan jenjang kelas, yaitu: disiplin, hidup bersih, ramah, sopan-santun, syukur nikmat, hidup sederhana, rendah hati, jujur, rajin, percaya diri, kasih sayang, taat, rukun, tolong-menolong, hormat dan patuh, sidik, amanah, tablig, fathanah, tanggung jawab, adil, bijaksana, teguh pendirian, dermawan, optimis, qana'ah, dan tawakal.

Pendapat yang demikian juga dikemukakan oleh Ahmad Al-Hasyim (2000:52) "Barangsiapa yang menghendaki kebaikan di dunia maka dengan ilmu. Barangsipa yang menghendaki kebaikan di akhirat maka dengan ilmu. Barangsiapa yang menghendaki keduanya maka dengan ilmu" (HR. Bukhori dan Muslim). Hadist tersebut adalah hadist yang menjelaskan tentang pentingnya sebuah pendidikan, karena tanpa sebuah pendidikan tidak akan ada ilmu yang bisa di dapatkan. Dan pada dasarnya semua yang ada di dunia, bahkan kelak di akhirat ilmu akan selalu berguna dan dibutuhkan oleh manusia. Seperti yang dijelaskan diatas, bahwasanya siapa yang menghendaki kebaikan hendaknya menggunakan ilmu, dan untuk menuju kebahagiaan diakhirat pun, ilmu sangatlah berguna. Dan dari sebuah ilmu itulah sebuah kesuksesan yang diharapkan akan tercapai.

Dalam pembelajaran akidah-akhlak mengandung makna sebuah usaha yang sadar dilakukan untuk merubah tingkah laku, peningkatan kualitas diri dan mengetahui suatu hal yang belum diketahui dan perlu untuk diketahui. Sedangkan akidah diartikan sebagai sebuah keyakinan kepada Allah yang tertanam dalam hati. Sedangkan akhlak mempunyai arti sebuah sikap, perilaku atau perbuatan yang tertanam atau menjadi kebiasaan, yang kadang sering dilakukakan tanpa harus berpikir panjang. Dalam pembelajaran yang dilakukan disini difokuskan pada pembelajaran Akidah akhlak, yang mana dapat kita ambil kesimpulan bahwasanya pembelajaran akidah-akhlak adalah: upaya yang sadar dilakukan untuk membentuk dan memperkuat keyakinan terhadap Allah dalam peningkatan kualitas diri dalam perilaku yang baik dan terpuji baik terhadap diri sendiri maupun orang lain.

Menurut Muhammad Ali Hasan (dalam Rosihon Anwar, 2008: 208) dalam Islam, dasar atau alat pengukur yang menyatakan baik buruknya sifat seseorang itu adalah Al-Qur'an dan As-Sunnah Nabi SAW. Apa yang baik menurut Al-Qur'an dan As-Sunnah, 
itulah yang baik untuk dijadikan pegangan dalam kehidupan sehari-hari. Sebaliknya, apa yang buruk menurut Al-Qur'an dan As-Sunnah, itulah yang tidak baik dan harus dijauhi.

Beberapa pernyataan di atas, setelah peneliti analisis bahwa mata pelajaran akidah-akhlak berimplikasi pada keyakinan dan akhlak manusia. Namun, di sini peneliti hanya membahas bagian akhlak saja. Di bawah ini peneliti menyajikan beberapa teori yang berkaitan dengan akhlak.

Pernyataan selanjutnya dikemukakan Amr Khalid (dalam Rosihon Anwar. 2010: 26-28) adapun tujuan akhlak adalah:

1. Mengetahui Tujuan Utama Diutusnya Nabi Muhammad SAW

Mengetahuinya tujuan utama diutusnya Nabi Muhammad SAW. tentunya akan mendorong kita untuk mencapai akhlak mulia karena ternyata akhlak merupakan sesuatu yang paling penting dalam agama. Akhlak bahkan lebih utama daripada ibadah. Sebab tujuan utama ibadah adalah mencapai kesempurnaan akhlak. Jika tidak mendatangkan akhlak mulia, ibadah hanya merupakan gerakan formalitas saja.

2. Menyatukan kerenggangan antara akhlak dan ibadah

Tujuan lain mempelajari akhlak adalah menyatukan antara akhlak dan ibadah, atau dalam ungkapan yang lebih luas antara agama dan dunia. Kesatuan antara akhlak dan ibadah, misalnya diperlihatkan oleh Rasulullah SAW. dalam sabdanya: Artinya:" Demi Allah tidak beriman, demi Allah tidak beriman, demi Allah tidak beriman. Ditanya, "Siapa ya Rasulullah?" Jawab Nabi, 'Orang yang tetangganya merasa tidak aman dari gangguannya." (H.R. Bukhari dan Muslim).

Hadis diatas dengan jelas mengecam orang yang mengaku beriman (ibadah), tetapi tidak memberikan keamanan kepada tetangganya (akhlak). Usaha menyatukan antara ibadah dan akhlak, dengan bimbingan hati yang diridai Allah SWT. dengan keikhlasan, akan terwujud perbuatan-perbuatan yang terpuji, yang seimbang antara kepentingan dunia dan akhirat serta terhindar dari perbuatan tercela.

3. Mengimplementasikan Pengetahuan tentang Akhlak dalam Kehidupan

Tujuan lain dari mempelajari akhlak adalah mendorong kita menjadi orangorang yang mengimplementasikan akhlak mulia dalam kehidupan sehari-hari. 
Menurut Nogarsyah Moede Gayo, (2004:39) bahwa "tujuan akhlak adalah hendak menciptakan manusia agar menjadi makhluk yang tinggi dan sempurna serta membedakannya dari makhluk-makhluk yang lain."

Dengan demikian, peneliti menyimpulkan bahwa tujuan akhlak adalah untuk memberikan pedoman atau penerang bagi manusia dalam mengetahui perbuatan yang baik atau buruk. Terhadap perbuatan yang baik ia berusaha melakukannya, dan terhadap perbuatan yang buruk ia berusaha untuk menghindarinya.

Menurut Ahmad Mustofa (1997:26) menyatakan “orang yang berakhlak karena ketakwaan kepada Tuhan semata-mata, maka dapat menghasilkan kebahagiaan, antara lain:

1. Mendapat tempat yang baik di dalam masyarakat

2. Akan disenangi orang dalam pergaulan

3. Akan dapat terpelihara dari hukuman yang sifatnya manusiawi dan sebagai makhluk yang diciptakan oleh Tuhan

4. Orang yang bertaqwa dan berakhlak mendapatkan pertolongan dan kemudahan dalam memperoleh keluhuran, kecukupan, dan sebutan yang baik

5. Jasa manusia yang berakhlak mendapat perlindungan dan segala penderitaan dan kesukaran.

Sedangkan menurut Barmawi Umari (dalam Ahmad Mustofa, 1997: 31) disebutkan bahwa:

1. Ilmu akhlak, dapat mengetahui batas antara yang baik dengan yang buruk dan dapat menempatkan sesuatu pada tempatnya, yaitu menempatkan sesuatu pada proporsi yang sebenarnya.

2. Berakhlak, dapat memperoleh isyad, taufiq dan hidayah yang dengan demikian maka Isnya Allah kita akan berbahagia di dunia dan di akhirat.

Menurut Ahmad Amin (dalam Zahiruddin dan Hasanudin Sinaga , 2004: 16) manfaat mempelajari ilmu akhlak itu adalah sangat penting dan mendasar diantara urgensinya bahwa:

1. Dapat menyinari orang dalam memecahkan kesulitan-kesulitan rutin yang dihadapi manusia dalam hidup sehari-hari yang berkaitan dengan perilaku.

2. Dapat menjelaskan kepada orang untuk memelih perbuatan yang baik dan lebih bermanfaat. 
3. Dapat membendung dan mencegah kita secara kontinyu untuk tidak terperangkap kepada keinginan-keinginan nafsu, bahkan mengarahkannya kepada hal yang yang positif dengan menguatkan unsur iradah.

4. Mengerti perbuatan baik akan menolong untuk menuju dan menghadapi perbuatan itu dengan penuh minat dan kemauan.

5. Orang yang mengkaji ilmu akhlak akan tepat dalam memvonis perilaku orang banyak dan tidak akan mengekor dan mengikuti sesuatu tanpa pertimbangan yang matang lebih dahulu.

Menurut Abuddin Nata ( 2011:173-176) bahwa "manfaat akhlak di antaranya adalah:

1. Memperkuat dan Menyempurnakan Agama

2. Mempermudah Perhitungan Amal Di Akhirat

3. Menghilangkan Kesulitan

4. Selamat hidup Di Dunia dan Akhirat."

Dengan demikian, peneliti menyimpulkan bahwa manfaat akhlak adalah memberi jaminan seseorang menjadi baik dan sopan dan membuka mata hati seseorang untuk mengetahui suatu perbuatan baik dan buruk, selain itu juga memberikan apa manfaatnya jika berbuat baik dan apa pula bahayanya jika berlaku jahat.

\section{PEMBAHASAN}

Berdasarkan hasil wawancara melalui via telepon, peneliti menjabarkan gambaran umum sejarah Dusun Sungai Jambu. Menurut Datuk Mu'in selaku ketua adat dan tokoh agama bahwa Dusun Sungai Jambu disebut sebagai dusun yang mana dulunya di tepi sungai banyak pohon-pohon jambu. Oleh karena itu, maka disebut nama Dusun Sungai Jambu. Kedua, wawancara dengan Muhammad Junaidi selaku Dusun Sungai Jambu yang menyatakan bahwa jumlah penduduk Dusun Sungai Jambu adalah dengan total KK (kartu keluarga) sebanyak 210 dan jumlah warga sebanyak 562 orang dengan penganut Agama Islam dan penganut Agama Budha dalam satu KK terdiri dari tujuh orang. Ketiga, pekerjaan Masyarakat Melayu Dusun Sungai Jambu Kabupaten Kayong Utara terdiri dari 50\% sawit, 30\% petani dan 10\% nelayan. Dari gambaran umum Dusun Sungai Jambu di atas, bahwa terdapat beberapa suku pada 
masyarakat tersebut yaitu suku Melayu penganut Agama Islam dan Suku Sakya penganut Agama Budha.

Bentuk kebudayaan masyarakat Melayu Dusun Sungai Jambu memiliki kearifan lokal yang ada pada tradisi berandep di ladang yang dilaksanakan satu tahun sekali. Berandep di ladang adalah aktivitas masyarakat Melayu Dusun Sungai Jambu yang dilaksanakan secara gotong royong (kerja sama) pada saat menanam (nandor padi) dan memanen padi (mengetam padi) dengan tujuan agar mempermudahkan pekerjaan cepat selesai. Selain itu, berandep di ladang dilaksanakan pagi hari mulai dari jam 06:30-10:30 WIB.

Dalam pelaksanaan berandep terbentuk sebanyak 4-6 orang dan dilaksanakan secara bergiliran. Apabila salah satu di antaranya mendapatkan giliran menanam dan memanen padi perlengkapan yang harus disiapkan adalah penugal (alat untuk membuat lubang untuk menanam padi), pengetam yang terbuat dari kayu dan ditempelkan silet pada kayu yang sedikit dibuat lubang agar siletnya mudah menempel agar mempermudah untuk mengetam (memanen padi), dan yang terakhir membawa makanan serta minuman untuk pelaku berandep. Hal ini dilakukan untuk menolong pelaku berandep tidak kesulitan ketika menandor atau menanam dan memanen padi.

Berdasarkan penelitian tradisi berandep di ladang, peneliti menemukan bahwa dari pelaksanaan tradisi berandep tersebut terdapat perilaku yang mengarahkan pada kerja sama dan tolong-menolong terhadap sesama yang terdapat pada mata pelajaran akidah-akhlak. Namun di sini, peneliti hanya membahas, menganalisis dan menawarkan bahwa tradisi berandep di ladang termasuk dalam ruang lingkup akhlak terhadap sesama manusia. Oleh karena itu, peneliti akan mengulas dan mengembangkan penemuan yang telah ditemukan di lapangan serta mengaitkannya dengan mata pelajaran akidah-akhlak yang di dalam mata pelajaran tersebut membahas materi kerja sama dan tolong-menolong. Di bawah ini, peneliti akan memaparkan beberapa teori akhlak yang relevan dengan hasil temuan di lapangan.

Menurut Zakiah Darajat (dalam Rosihon Anwar, 2008: 215) bahwa akhlak terhadap sesama manusia adalah suka menolong orang lain. Dalam hidup ini, setiap orang pasti memerlukan pertolongan orang lain. Adakalanya karena sengsara dalam hidup, penderitaan batin atau kegelisahan jiwa, dan adakalanya karena sedih setelah mendapat berbagai musibah. 
Nasharuddin (2015:273) menegaskan, "saling membantu dan saling tolongmenolong menjadi penting dalam mencapai masyarakat madani. Itu sebabnya, Nabi menganjurkan kehidupan sesama Muslim itu laksanakan kehidupan bersaudara. Dalam al-Qur'an disebutkan, bahwa kaum muslimin itu adalah bersaudara. Akhlak antar sesama, merupakan bagian dari ketakwaan seseorang. Dalam hadis di bawah ini, ada tiga perintah, yaitu bertakwalah kepada Allah, ikuti yang buruk itu dengan yang baik dan berprilaku baik antarsesama manusia.

Hal senada juga dinyatakan oleh Saad Riyadh (2007:113-114) menegaskan, "Dalam hadist-hadistnya, Rasulullah saw. banyak menyeru kita untuk tolong-menolong atau bahu membahu. Dengan demikian, akan terbentuk masyarakat yang kokoh laksana benteng yang masing-masing komponennya saling menguatkan, atau laksana satu tubuh yang jika salah satu bagian sakit maka yang lain juga akan ikut merasakan. Rasulullah saw. bersabda: "Siapa saja (di antara orang-orang mukmin) yang melapangkan satu kesusahan dunia yang dialami mukmin yang lain maka Allah swt. akan melapangkan satu kesusahan darinya di hari akhirat. Siapa saja yang menutub aib (kejelekan) seorang muslim maka Allah swt. juga akan menutub aibnya, baik di dunia maupun di akhirat. Sesungguhnya Allah swt. akan selalu menolong seorang hamba selama ia tetap menolong saudaranya (sesama muslim)." (HR Tirmidzi)

Berdasarkan teori tersebut, maka temuan dari penelitian ini bahwa tradisi berandep di ladang relevansinya terletak pada materi kerja sama dan tolong-menolong yang telah dituangkan dalam mata pelajaran akidah-akhlak. Oleh karena itu, dalam penelitian ini lebih menekankan pada ruang lingkup akhlak terhadap sesama manusia dan sebagaimana tercantum pada materi kerja sama dan tolong-menolong.

\section{KESIMPULAN}

Dari uraian diatas, peneliti menyimpulkan bahwa kegiatan gotong royong (kerja sama) dan tolong-menolong pada masyarakat Melayu Dusun Sungai Jambu sangat terpelihara kelestariannya. Dengan adanya kegiatan gotong royong (kerja sama) dan tolong-menolong mempermudahkan pekerjaan cepat selesai.

Bila dikaji secara saksama, dalam kegiatan gotong-royong (kerja sama) dan tolong-menolong masyarakat Melayu Dusun Sungai Jambu terkandung nilai-nilai kebersamaan, nilai membiasakan diri untuk bersedekah, mempererat hubungan silaturrahmi dan solodaritas sosial yang bermanfaat bagi keselarasan hidup 
bermasyarakat pada masa kini. Nilai-nilai tersebut dalam tradisi gotong-royong dan tolong-menolong dapat disosialisasikan kepada generasi penerus khususnya generasi muda sebagai kelompok sosial yang akan melanjutkan kehidupan masa akan datang guna membentuk budi pekerti serta dalam menghadapi berbagai pergeseran nilai pada era budaya global.

\section{DAFTAR PUSTAKA}

Abduh Gholib Ahmad Isa. 2010. Etika Pergaulan Dari A-Z. Solo:Pustaka Arafah.

Abdulsyani, 1994. Sosiologi Skematika, Teori, dan Terapan, Jakarta: Bumi Aksara.

Abudin Nata. 2011. Akhlak Tasawuf. Jakarta. PT. GrafindoPersada.

Ahmad Mustofa. 2010. Akhlak Tasawuf. Bandung: Pustaka Setia.

Ahmad Al-Hasyim. 2000. Kitab Hadits Nabawiyah. Semarang: Toha Putra.

Andi Prastowo. 2015. Pembelajaran Konstruktivistik-Scientific Untuk Pendidikan Agama di Sekolah/Madrasah. Jakarta: RajaGrapindo.

Barmawie Umarie. 1995. Materi Akhlak. Solo: Ramadhani.

Kuswarno, Engkus. 2011. Etnografi Komunikasi: Pengantar dan Contoh Penelitiannya. Bandung: Widya Padjadjaran.

Kementerian Agama RI (2011). Al-Qur"an dan Tafsirnya, (Edisi yang Disempurnakan), jilid II. Jakarta: Widya Cahaya.

M. Quraish Shihab. 2002. Tafsir Al Misbah. Jakarta Lentera Hati.

Nasharuddin. 2015. Akhlak (Ciri Manusia Paripurna). Jakarta: PT Raja Grapindo Persada.

Nurul Hidayati Rofiah. 2016. "Desain Pengembangan Pembelajaran Akidah Akhlak Di Perguruan Tinggi" dalam Fenomena, Volume 8 (1): 58-59.

Nogarsyah Moede Gayo. 2004. Kamus Istilah Agama Islam. Jakarta: Progres.

Peraturan Menteri Agama Republik Indonesia Nomor 2 Tahun 2008 tentang Standar Kompetensi Lulusan dan Standar Isi Pendidikan Agama Islam dan Bahasa Arab di Madrasah Mata pelajaran Akidah-Akhlak di Madrasah Ibtidaiyah.

Rosihon Anwar. 2008. Akidah Akhlak. Bandung: CV Pustaka Setia. 2010. Akhlak Tasawuf. Bandung: CV Pustaka Setia. 
70 | Dewi Hurhayati \& Wahab

Saad Riyadh. 2007. Jiwa Dalam Bimbingan Rasulullah. Jakarta: Gema Insani.

Salamun, dkk. 2002. Budaya Masyarakat Suku Bangsa Jawa di Kabupaten Wonosbo Provinsi Jawa Tengah. Yogyakarta: Badan Pengembangan dan Kebudayaan Pariwisata.

Sugeng Mulyono. 2015. Berguru kepada Pak Sahlan Nawar. linkarborneo.org. Download 12 Desember 2016.

Wahab. (2015). Sapa And Base Communication Of Sambas Society: A Case Of MalayMadurese Post-Conflict 1999-2014: Of Scientific And Technology Research. Vol 4 (2) :254.

Winardi. 2009. Membina Akidah dan Akhlak 3. Solo: Tiga Serangkai Pustaka Mandiri.

Zahruddin dan Hasanuddin Sinaga. 2004. Pengantar Studi Akhlak. Jakarta: PT. Grapindo Persada. 